\title{
DOSSIÊ
}

\section{Caso Rafael Braga como evidência da subcidadania e seus reflexos no sistema}

\section{penal}

\author{
Mayara Lorena Barbosa de Almeidal
}

Como citar este artigo: ALMEIDA, Mayara Lorena Barbosa de. Caso Rafael Braga como evidência da subcidadania e seus reflexos no sistema penal. Revista de Ciências do Estado. Belo Horizonte: v. 6, n. 1, 2021, e25136. ISSN: 2525-8036.

Resumo: Flagrantes arbitrariedades e ilegalidades permeiam os aparelhos relacionados ao sistema e ao direito penal brasileiro: milícias, chacinas e sistemáticas violações de direitos humanos em presídios são recorrentes e até mesmo naturalizadas. Este trabalho propõe compreender o sistema e o direito penal tendo em vista a categoria da subcidadania no contexto brasileiro. A partir do caso do jovem Rafael Braga, preso em 2013 nas Jornadas de Junho, analisamos o cenário brasileiro sob à luz da teoria crítica enquanto método de evidenciação das estruturas e ideologias dominantes, mas também como metodologia capaz de evidenciar lutas e propostas emancipatórias. Ademais, apresentamos dados que corroboram relevantes marcadores sociais na construção da criminalidade. Nossa hipótese é que o caso Rafael Braga expõe a regra, e não a exceção do moderno modelo penal que, em sociedades periféricas como a brasileira, evidencia a desigualdade estrutural e a fragilidade da cidadania. Os resultados apontam para a inadequação do modelo punitivo para a efetividade da cidadania e dos direitos humanos como pressupostos do Estado Democrático de Direito. Conclui-se que é necessário superar o modelo normativo de controle social a fim de reduzir as discrepâncias sociais que no Brasil produzem subcidadãos.

Palavras-chave: Cidadania; Sistema Penal; Direito Penal

\section{INTRODUÇÃO}

A vida de Rafael Braga (1988-) ganhou notoriedade nacional após sua condenação por porte ilegal de artefato incendiário, o que o fez o único condenado das Jornadas de Junho de 2013. A indignação de movimentos sociais e defensores de direitos humanos reacendeu o

\footnotetext{
${ }^{1}$ Graduada em História (2015) e Ciências do Estado (2021) pela Universidade Federal de Minas Gerais (UFMG). Participou do Programa de Iniciação Científica Voluntária (ICV) da Pró-Reitoria de Pesquisa (PRPq) da UFMG e do Projeto de Políticas Públicas Baseadas em Evidências da Faculdade de Direito da UFMG. Tem experiência em docência e assessoramento político. Possui interesse nas áreas de Direitos Humanos, Feminismo, Participação Popular e Democracia. Contato: mayara.ufmg.historia@gmail.com
} 
debate sobre a seletividade da justiça, o racismo institucional, a desigualdade social e a vulnerabilidade aos quais estão submetidos quase um terço da população brasileira. O tema, que nunca saiu de pauta, buscava explorar, por meio do caso de Rafael Braga, a rotina do direito e do sistema penal pátrio. O país com a terceira maior população carcerária em números absolutos do mundo lançava suas garras sobre mais um jovem preto e pobre.

Entende-se, portanto, que o caso de Rafael Braga reflete um processo sócio-histórico de exclusão e hierarquização que, em países periféricos como o Brasil, alcança boa parte da população. O fenômeno, denominado por Jessé Souza (2018) de subcidadania, explicita a construção da ideologia espontânea do capitalismo e a conformação de um habitus precário que perpetua a desigualdade por gerações.

A subcidadania não está limitada à valoração intersubjetiva dos sujeitos na sociedade, mas compõe a materialidade da existência humana. São subcidadãos os(as) moradores(as) de favelas, os(as) sem-teto, sem-terra, travestis e transexuais, indígenas, quilombolas, ciganos(as), homens e mulheres marcados física e mentalmente pela desigualdade estrutural e a falta de oportunidades.

Por fim, o direito e o sistema penal compõem os instrumentos lícitos do sistema capitalista de produção de descarte de subcidadãos. Conforme José Murilo de Carvalho (2002), esses cidadãos de terceira categoria, não se sentem protegidos pela sociedade e pelas leis, pois seu contato com os agentes do poder estatal ocorre sempre em prejuízo próprio, isto é, para eles o único direito que lhes cabe está inscrito no Código Penal.

Nesse sentido, pretendemos compreender o sistema e o direito penal tendo em vista a categoria da subcidadania, além de analisar o caso de Rafael Braga como evidenciação desta e seus reflexos. Propomos apresentar as bases de uma criminologia crítica capaz de explicar as origens e sentidos do direito e do sistema penal no sistema capitalista, ao mesmo tempo em que exploramos possibilidades emancipatórias. Nossa hipótese é que o caso Rafael Braga expõe a regra e não a exceção do moderno sistema penal que, em sociedades periféricas como a brasileira revela a desigualdade estrutural e a fragilidade da cidadania.

A partir de uma teoria crítica da modernidade e da modernização, tal como proposta por Jessé Souza (2018), apresentamos o conceito de subcidadania brasileira e seus reflexos no direito e no sistema penal. Os dados do Levantamento Nacional de Informações Penitenciárias (Infopen) e do Conselho Nacional de Justiça (CNJ) visam sustentar e corroborar esse estudo.

O que se segue é a exposição do caso de Rafael Braga desde 2013 até o presente ano com todas as suas contradições para, a partir de então, apresentar a tese da subcidadania e as consequências desse fenômeno no sistema e no direito penal. 
Conclui-se que, diante dos princípios que norteiam o Estado Democrático de Direito, faz-se necessário superar o modelo punitivista de controle social que retroalimenta as desigualdades e a produção de subcidadãos.

\section{HISTÓRICO DO CASO RAFAEL BRAGA}

Rafael Braga Vieira (31/01/1988) é um jovem negro, pobre e periférico que ganhou notoriedade ao ser o único condenado das Jornadas de Junho de 2013. No dia 20 de junho de 2013, em meio a milhões de pessoas presentes no ato no centro do Rio de Janeiro, Rafael Braga foi detido pelos policiais Erik Duarte Correa e Eduardo Nogueira Vieitos quando chegava a um casarão abandonado, onde por vezes dormia. Ele não participou das manifestações e apenas carregava consigo duas garrafas de plástico, uma de Pinho Sol e outra de desinfetante. Na delegacia, os policiais que o detiveram apresentaram as garrafas abertas e com panos e o acusaram de portar material explosivo que seriam coquetéis molotov.

Rafael passou 5 meses no Complexo Penitenciário de Japeri aguardando julgamento, sendo assistido por um defensor público. No dia 23 de setembro do mesmo ano, foi protocolado um pedido de revogação da prisão preventiva de Rafael Braga pela Defensoria Pública, julgado improcedente pelo juiz da $32^{\mathrm{a}}$ Vara Criminal no dia 27 do mesmo mês.

Nesse processo, um laudo tendencioso e contraditório da Polícia Civil sobre a prisão de Rafael Braga afirmava que o acusado portava instrumentos com a intenção de criar um coquetel molotov. No laudo técnico produzido pelo Esquadrão Antibombas da Coordenadoria de Recursos Especiais (CORE), consta que, introduzidos nos gargalos das duas garrafas plásticas que Rafael levava, havia pavios, isto é, "mechas ignotoras", e que um dos frascos continha material inflamável "apto a ser acionado [por chama] e lançado". Ainda assim, contraditoriamente, a conclusão da perícia foi de que o material apreendido apresentava "mínima aptidão para funcionar como coquetel molotov", já que se encontrava em garrafa plástica. Todas as testemunhas ouvidas no processo eram policiais.

Os depoimentos de Erik Duarte Correa e Eduardo Nogueira Vieitos, os policiais civis que detiveram Rafael, foram uníssonos e corroborados pelo também policial Elington Cacella Vieira.

A primeira condenação de Rafael Braga teve alguma repercussão em matérias de jornais. A partir de então, ativistas, militantes, coletivos e movimentos sociais ficaram cientes de que ele ainda estava preso. Essa publicização do caso possibilitou que a defesa de Rafael Braga fosse assumida pelo Instituto dos Defensores de Direitos Humanos (IDDH). A nova 
defesa de Rafael Braga alegou na ocasião que o conteúdo das garrafas não era explosivo, que o laudo da CORE reconhecia que os materiais apontavam aptidões mínimas de incêndio ("ínfima”), e que as duas garrafas, anteriormente lacradas, passaram a garrafas abertas com líquido adulterado e pedaços de pano em seus bocais.

Mesmo assim, em 2 de dezembro de 2013, o juiz Guilherme Schilling Pollo Duarte, da 32 ${ }^{\text {a }}$ Vara Criminal do Rio de Janeiro, condenou Rafael Braga a 5 anos de prisão em regime inicial fechado, sendo 4 anos por porte ilegal de artefato incendiário (Artigo 16, Parágrafo Único, Inciso III, do Estatuto do Desarmamento), 1 ano por reincidência, mais pagamento de 10 dias-multa e custas processuais. O juiz também determinou a destruição dos artefatos apreendidos, tornando impossível uma revisão da perícia.

Os recursos de apelação e embargos declaratórios apresentados pela defesa apontavam todas as contradições da prisão e de adulteração e destruição das provas. Mas, no dia 26 de agosto de 2014, a $3^{\text {a }}$ Câmara Criminal do Tribunal de Justiça do Rio de Janeiro decidiu manter a prisão de Rafael Braga, diminuindo sua pena em apenas 4 meses. Além disso, um recurso extraordinário referente à condenação em primeira instância chegou ao Supremo Tribunal Federal (STF) em 2015, porém não foi aceito.

Em outubro de 2014, houve a progressão de regime de Rafael Braga, de fechado para o semiaberto, quando poderia sair do presídio para trabalhar. Ele começou então a trabalhar no escritório do IDDH como auxiliar de serviços gerais.

No mês seguinte, posou para uma fotografia ao lado do portão do presídio, em cujo muro estava pichada a frase "Você só olha da esquerda p/ a direita, o Estado te esmaga de cima p/ baixo!!!.” A imagem foi postada na página do Facebook do IDDH, o que rendeu a Rafael Braga uma nova punição, imposta pela diretora do instituto penal: 10 dias de permanência numa cela solitária por infração do inciso XV, do Artigo 59, do Regulamento do Sistema Penal do Estado do Rio de Janeiro - "veicular de má-fé, por meio escrito ou oral, crítica infundada à administração prisional”.

Por conta do ocorrido, o Ministério Público do Rio de Janeiro solicitou a regressão do regime semiaberto para fechado por entender que houve evasão. Entretanto, a Vara de Execuções Penais do Rio de Janeiro não acatou o requerimento e acolheu integralmente o pedido da defesa, para Rafael continuar no semiaberto e trabalhando.

Em $1^{\circ}$ de dezembro de 2015 , ele obteve o direito de cumprir prisão domiciliar na casa de familiares, mediante o uso de tornozeleira eletrônica.

Em 12 de janeiro de 2016, Rafael Braga foi preso novamente em flagrante forjado por policiais da $7^{a}$ Unidade da Polícia Pacificadora (UPP), sob a acusação de tráfico de drogas 
e associação ao tráfico. Ele foi conduzido à $22^{\mathrm{a}}$ Delegacia de Polícia (DP), no bairro da Penha, e somente ali, de acordo com o advogado, se deparou com 0,6 g de maconha, 9,3 g de cocaína e um rojão, cujo porte lhe foi falsamente atribuído pelos policiais que o prenderam. Segundo a vítima, ele foi chamado de "bandido" e agredido com chutes e socos pelos policiais, para que desse informações relacionadas ao tráfico.

Em depoimento, o policial militar Pablo Vinícius Cabral disse que, antes de ser levado à $22^{\mathrm{a}} \mathrm{DP}$, Rafael Braga esteve na UPP Vila Cruzeiro e foi conduzido na caçamba da viatura. Já o outro policial que também depôs contra Rafael Braga, Victor Hugo Lago, disse que ele foi levado diretamente para a delegacia e no banco de trás da viatura.

Por conta dessas inconsistências, a defesa de Rafael solicitou acesso ao registro legível do GPS da tornozeleira eletrônica que o ex-catador usava durante seu regime aberto, às imagens da câmera da viatura policial que o conduziu e às imagens da câmera da UPP Vila Cruzeiro. A defesa também arrolou como testemunha uma vizinha da família, que afirmou ter visto Rafael Braga no momento da prisão sem nenhum saco plástico sendo agredido e arrastado pelos policiais para fora de seu campo de visão.

O juiz Ricardo Coronha Pinheiro, da $39^{\mathrm{a}}$ Vara Criminal do Rio de Janeiro, negou todos os pedidos, com o argumento de que as informações eram desnecessárias para o desfecho do processo, além de afirmar que a testemunha da defesa, em razão de seus "laços com a família”, estaria comprometida em suas declarações. Este juiz, em 20 de abril de 2017, condenou Rafael a 11 anos e 3 meses de reclusão em regime inicial fechado e pagamento de dias-multa, por tráfico de drogas e associação ao tráfico.

Percebe-se que toda a acusação contra Rafael Braga foi baseada apenas na palavra dos policiais que o prenderam, mesmo havendo uma testemunha que desmente o policial e afirma que o flagrante teria sido forjado. Isso é possível porque a Súmula 70, uma diretriz do Tribunal de Justiça do estado do Rio de Janeiro, dá total poder à palavra dos policiais no momento do julgamento.

Em 19 de julho de 2017, foi protocolado pela defesa o recurso de apelação à sentença do juiz Ricardo Coronha Pinheiro. Os pontos levantados pela defesa foram referentes à manutenção das algemas de Rafael Braga durante a audiência e de diligências consideradas necessárias para o esclarecimento do caso.

O juiz justificou a ordem para que as algemas fossem mantidas com a afirmação de que se tratava de um caso de repercussão pública e que ele temia que o réu pudesse oferecer perigo à segurança dos presentes. A segunda nulidade se refere ao fato de o juiz Ricardo 
Coronha ter negado o pedido de diligências da defesa, sob o argumento de que as imagens das câmeras seriam desnecessárias para o desfecho do processo.

Dias depois, o habeas corpus impetrado pela defesa de Rafael Braga, em primeiro de agosto de 2017 no TJ-RJ, foi negado. O documento que requeria a libertação do réu cita, inclusive, a posição do STF no reconhecimento de que até mesmo pessoas pertencentes a poderosos grupos econômicos e políticos, e acusados de corrupção e desvio de recursos públicos, têm direito a responder em liberdade, então por que não oferecer a mesma garantia para um pobre, morador de favela, semianalfabeto?

De volta à penitenciária, no dia 17 de agosto, Rafael Braga foi internado na Unidade de Pronto Atendimento e Hospital Dr. Hamilton Agostinho Vieira, no Complexo Penitenciário de Gericinó, com suspeita de tuberculose. Mas, somente quando Adriana Braga, mãe de Rafael, foi visitá-lo no domingo, é que foi informada sobre a internação.

O sistema prisional brasileiro tem 28 vezes mais incidência de casos de tuberculose do que entre a população em geral, devido à superlotação e à falta de ventilação e luz solar nas penitenciárias. Segundo especialistas, os detentos respondem por $7 \%$ dos novos casos da doença a cada ano no Brasil.

Um relatório feito pela Defensoria Pública do Rio de Janeiro apresentado em maio de 2017 demonstrou o nível de insalubridade dentro da Penitenciária de Bangu 2, onde Rafael Braga estava preso. O resultado revelou que a cadeia estava com superlotação, haja vista a capacidade para 881 presos e a instituição abrigar 3.087, praticamente quatro vezes mais. Os presos convivem nas celas juntamente com insetos, baratas, ratos e percevejos.

No dia 13 de setembro de 2017, o Superior Tribunal de Justiça (STJ) concedeu prisão domiciliar para Rafael Braga.

Por fim, em 22 de novembro de 2018, Rafael Braga foi absolvido do crime de associação ao tráfico de drogas, em decisão da $1^{\text {a }}$ Câmara Criminal do Rio de Janeiro. Atualmente ele segue respondendo pelo crime de tráfico de drogas.

\section{O PROBLEMA DA CIDADANIA NA PERIFERIA DO CAPITALISMO}

Narrar toda a história da prisão de Rafael Braga, com suas sinuosidades e flagrantes injustiças, pretende evidenciar como opera o sistema judiciário e penal no Brasil. Mas, antes de falar sobre seletividade da justiça, racismo institucional e encarceramento em massa, precisamos dizer que estas são consequências de um fenômeno mais antigo e profundo que conforma a sociabilidade brasileira. 
A produção de subcidadãos ou não-cidadãos no Brasil já foi analisada por vários sociólogos e historiadores a começar por José Murilo de Carvalho (2002), que afirma que a cidadania no Brasil está incompleta e expõe a existência de três categorias de cidadãos no país: os "doutores" ou cidadãos de primeira classe; os "cidadãos simples" ou cidadãos de segunda classe e; os "elementos" ou cidadãos de terceira classe. De acordo com o autor, cada uma dessas parcelas de cidadãos têm diferentes graus de relação com seus direitos e com o próprio Estado.

Já Roberto DaMatta (1989), compreende que as relações pessoais e familiares estendem-se para a área pública numa confusão entre público e privado, de modo que existe uma expectativa de distinção e hierarquização na distribuição de direitos no Brasil.

Outra hipótese, elaborada por Oscar Vilhena Vieira (2007), aponta para o fato de que a exclusão social e econômica decorrente de abismais níveis de desigualdade no país, invisibiliza os pobres, demoniza aqueles que desafiam o sistema e imuniza os privilegiados, impedindo assim que a lei seja de fato imparcial.

Por fim, Acácio Augusto (2013), tendo por base a filosofia foucaultiana, aproxima as práticas de cidadania às práticas policiais, e afirma que há nas sociedades contemporâneas uma expansão da subjetividade policial em cada cidadão, de modo que, cada um age como um policial-consumidor-empresa de si e dos outros.

Diante dessas contribuições, nos interessa analisar mais profundamente a teoria produzida por Jessé Souza (2018), por entendermos que sua narrativa rompe com o paradigma culturalista que explica a desigualdade no Brasil como fruto de uma herança ibérica, focalizando o problema nas próprias estruturas da modernidade capitalista. A partir de uma teoria crítica da modernidade e da modernização, desenvolvida pelo autor, entendemos os nossos problemas como oriundos de relações de dominação destinadas a perpetuar as desigualdades e a miséria para manter privilégios.

Souza demonstra que, para além das lutas de classes que possibilitam acesso diferencial aos recursos e bens escassos, existe um limite abaixo da dignidade que caracteriza uma parcela da população mundial. No caso do Brasil, a "ralé" é a classe sem acesso aos capitais que proporcionam a incorporação da moderna ideia de alma, isto é, dignidade e autenticidade, mas também sem acesso aos pressupostos dessa incorporação. Para explicitar esse fenômeno, articulam-se duas dimensões que tornam invisíveis a realidade: a dimensão material, da pobreza econômica, e a dimensão simbólica, do não reconhecimento, sendo que essas são inseparáveis. 
Essas classes de desclassificados sociais são construídas por motivos modernos e semelhantes em qualquer lugar. Afinal, é a ausência da incorporação de modernos capitais impessoais, tanto o capital econômico quanto o capital cultural, que reduz os indivíduos dessa classe a corpos que são vendidos enquanto corpos, a baixo preço, para serviços desvalorizados. [...] É, por sua vez, a não incorporação desses capitais impessoais que implica uma realidade simbólica existencial e política precária para aqueles situados abaixo da linha divisória da dignidade, no sentido tayloriano. Essa concepção implica várias armadilhas para a análise científica que não são privilégio de brasileiros ou de cientistas da periferia. Também em nível mundial, a realidade dos excluídos é tornada invisível pelos mesmos 'inimigos': por um lado, a percepção liberal da sociedade que universaliza as disposições de comportamento da classe média para todas as classes subalternas, permitindo culpá-las pelo próprio fracasso, e por outro lado, a percepção politicamente correta que assume o discurso necessariamente reativo do excluído sobre si mesmo como sua verdade. (SOUZA, 2018, p. 49-50)

O não reconhecimento desses sujeitos permite o genocídio e encarceramento em massa de jovens negros pobres no Brasil.

De acordo com Fraser (2008), tanto raça, classe, gênero e sexualidade são categorias de subordinação bivalentes que implicam injustiças como má distribuição e não reconhecimento cujos remédios seriam redistribuição e reconhecimento, respectivamente.

Jessé Souza contesta a proposta da filósofa americana ao lembrar-nos que são os consensos culturais opacos e intransparentes que legitimam o acesso desigual a bens e serviços, e ressalta que em uma sociedade tão desigual como a nossa, o desafio da igualdade e da diferença são simultâneos e inexoráveis (SOUZA, 2018).

Portanto, aqui o fator escravidão é fundamental na explicação da hierarquização dos indivíduos e classes sociais conforme seus imperativos funcionais. $\mathrm{O}$ abandono dos libertos no nascer da República se relaciona ao desenvolvimento de um habitus precário. O não reconhecimento desses sujeitos como cidadãos e produtores não se dá tanto pela cor, afirma Souza, mas se refere ao desenvolvimento de um tipo de personalidade considerada improdutiva e disruptiva para a sociedade. Ou seja, “A marginalização permanente de grupos sociais inteiros tem a ver com a disseminação efetiva de concepções morais e políticas, que passam a funcionar como ideias-força nessas sociedades.” (SOUZA, 2018, p. 231).

Gente e cidadão pleno vão ser apenas aqueles indivíduos e grupos que se identificam com a concepção de ser humano contingente e culturalmente determinada que habita, de forma implícita e invisível, a consciência cotidiana, a hierarquia valorativa subjacente à eficácia institucional de instituições fundamentais como Estado e mercado e que constitui o cerne da dominação simbólica subpolítica que perpassa todas as nossas ações e os nossos comportamentos cotidianos. (SOUZA, 2018, p. 260)

Nessa perspectiva, temos aproximadamente um terço da população brasileira de subcidadãos. São pessoas que vivem abaixo da linha de pobreza e que, portanto, não incorporam e nunca poderão incorporar o valor europeizado de dignidade. São também os 
sujeitos descartáveis e matáveis da necropolítica (MBEMBE, 2016), atributo e limite da própria noção de soberania que impõe a várias populações o status de "mortos-vivos".

É empírico no Brasil que os sujeitos favelados, indígenas, transexuais/travestis, semterra, em situação de rua, ou seja, aqueles cujos direitos humanos universais e cidadãos são sistematicamente violados, são também aqueles cujas vidas são eliminadas e cujos corpos são desaparecidos ou arrastados sem nenhum pudor por agentes do aparato estatal.

Diante disso, confirmamos que o marcador étnico-racial é relevante e não se subjuga a questão de classe, como defende Souza. A partir das categorias de interseccionalidade (CRENSHAW, 2002) e consubstancialidade (KERGOAT, 2010) reconhecemos a multiplicidade dos sistemas de opressão que interagem na produção e reprodução das desigualdades sociais. Portanto, as relações de classe, raça e gênero se (re)produzem mutuamente sem que haja primazia de uma sobre a outra.

Logo, o fato de Rafael Braga ser negro é tão relevante na consumação de seu caso quanto o fato de ser pobre e estar em situação de rua. E o fato de ser subcidadão está marcado no seu corpo de modo que a presença do aparato estatal na sua vida se relaciona à opressão e a parte do direito que lhe cabe é a penal. Subcidadão por acordos invisíveis, inarticulados e imperceptíveis que hierarquizam sujeitos e grupos sociais, ditam quais vidas merecem ser vividas e quais podem ser interrompidas, permitindo, inclusive, o descarte de pessoas de forma institucionalizada.

\section{SISTEMA PENAL E DIREITO PENAL À LUZ DA CRIMINOLOGIA CRÍTICA}

O caso de Rafael Braga é apenas um exemplo que expõe a regra, e não a exceção, do moderno sistema criminal que, em sociedades periféricas, aprofunda e agudiza ainda mais as desigualdades. É sabido que o Brasil tem hoje a terceira maior população carcerária em números absolutos do mundo. O que muitos não sabem é quem são os sujeitos encarcerados.

Os dados do Levantamento Nacional de Informações Penitenciárias (Infopen) de 2019 apontavam 773.151 pessoas privadas de liberdade em todos os regimes. Destes, 39,4\% haviam cometido crimes relacionados à lei de drogas, $36,7 \%$ por crimes contra o patrimônio e $11,3 \%$ por crimes contra a pessoa. Do total de presos e presas, $21,5 \%$ têm entre 25 e 29 anos, $95,06 \%$ são do sexo masculino e, dentre estes, $66,69 \%$ são pretos e pardos.

Por outro lado, o Perfil Sociodemográfico dos Magistrados Brasileiros de 2018 apontava que os homens representam $63 \%$ dos magistrados que ingressaram na carreira a partir de 2011. Além disso, a idade média do magistrado brasileiro é 47 anos, sendo que $80 \%$ 
deles são casados ou vivem em união estável, $78 \%$ têm filhos, $80,3 \%$ são brancos e $26 \%$ de todos os magistrados que responderam ao questionário da Conselho Nacional de Justiça (CNJ) nasceram em São Paulo.

Mais uma vez, marcadores sociais relevantes que demonstram o abismo entre o julgador e o julgado no Brasil.

Em uma perspectiva criminológica crítica, entende-se que a criminalidade nada tem a ver com a política penal, mas se relaciona ao desenvolvimento econômico. Ou seja, o sistema penal de uma dada sociedade não é um fenômeno isolado sujeito às suas leis, e sim parte de todo o sistema social com quem compartilha aspirações e defeitos (RUSCHE; KIRCHHEIMER, 2004). No sistema capitalista de produção, o método punitivo de encarceramento tem por função reproduzir a ordem social capitalista, sendo, portanto, um serviço de controle da produção da desigualdade social, isto é, gestão, controle e domínio de classe. "A função da prisão, nesse segundo eixo deslegitimador, não é o combate à criminalidade, por meio da ressocialização, do castigo e da intimidação, é a construção de criminosos, é a fabricação de criminosos" (ANDRADE, 2014 apud NOVAIS, 2016, p. 126).

Ressalta-se que, por sistema penal entendemos o conjunto de agências que operam a criminalização (primária e secundária) ou convergem na sua produção. Estas agências funcionam de modo compartimentado, isto é, cada uma opera de acordo com seu próprio poder, seus interesses e respectivos controles. Portanto, não é possível atribuir seus resultados a uma manipulação, tal qual marionetes, de todas as agências do sistema penal. (ZAFFARONI et al., 2003, p. 60).

Segundo o princípio da legalidade, o sistema penal e seus órgãos devem exercer poder em acordo com a legislação. Todavia, percebe-se que o sistema penal age em desrespeito à legalidade, a exemplo da presunção de inocência que, no Brasil, nada mais é do que presunção de culpa, das inúmeras chacinas, do desenvolvimento e consolidação das milícias, das prisões ilegais, etc.

Impõe-se o fato de que o direito penal reflete uma contradição fundamental entre igualdade formal e desigualdade substancial entre os sujeitos de direito, que é ainda pior em países periféricos como o Brasil e outros latino-americanos. E, portanto, contradiz-se com os princípios de um Estado Democrático de Direito e com os fundamentos dos direitos humanos.

Um Estado Democrático de Direito que prega o respeito à cidadania, aos direitos humanos e ao combate às desigualdades sociais não pode lançar mão de uma forma de controle penal que institucionaliza a violência e a arbitrariedade, sem que antes tenha tentado o referido controle social através de políticas sociais agregadoras e construtoras de cidadania. 
O direito penal tem elevado custo social, por vezes irreversível, para a vítima (vitimização primária e secundária), para o criminoso (estigmatização) e para a sociedade (pânico, agressão aos direitos humanos). Uma política de transformação da realidade do sistema penal deve pautar-se em valores constitucionais e alcançar setores populares, não podendo considerar o direito penal como principal objeto. Pelo contrário, o Direito Penal, neste plano democrático, deve restar subsidiário. (LOPES, 2002, p. 168)

A Constituição da República (1988) assumiu uma orientação voltada para a redução dos danos produzidos pelo poder punitivo (teoria agnóstica da pena). Nessa perspectiva, reduzir o sofrimento, direcionar esforços para minimizar os riscos gerados pelos aparatos punitivos, bem como desnudar na esfera público-política a retórica penal constitui-se uma alternativa ética, teórica e instrumental possível na atual condição em que o direito penal é aplicado e tendo em vista os ideais expressos na Constituição (CARVALHO, 2013).

Porque a lógica do sistema penal é diametralmente oposta às exigências de uma cidadania plena e dos direitos humanos, o caso de Rafael Braga expõe a lógica subjacente à modernidade periférica brasileira. As práticas de racismo institucional, o fenômeno da subcidadania, o recrudescimento do autoritarismo, a militarização da política e a gestão da crise e da barbárie social são as várias faces da violência produzidas pelo sistema capitalista na periferia do mundo.

Por outro lado, a ressignificação e reconfiguração da cidadania se relaciona com as próprias lutas por reconhecimento e igualdade. Ou seja, a ressignificação e reconfiguração da cidadania na América Latina passa, necessariamente, pelo reconhecimento da dominação centro-periferia e por um processo de resistência e transformação que só pode ser realizado pelos próprios sujeitos oprimidos/dominados/pobres ao debater e recriar as instituições e reconhecer novos direitos em função de suas próprias lutas.

A legitimidade no Estado Democrático de Direito decorre do reconhecimento dos sujeitos como coautores das normas jurídicas, a qual se realiza apenas quando todos podem participar como iguais sem nenhum tipo de constrangimento ou violência na vida públicopolítica (CATTONI DE OLIVEIRA, 2012). Desse modo, a reconstrução e o fortalecimento da democracia dependem das ações dos cidadãos desde o interior da própria realidade, considerando a pluralidade sociocultural e política, assim como as várias concepções de vida boa.

Por isso, Lopes (2002) propõe (re)legitimar o sistema penal e, consequentemente, o próprio direito, tendo em vista que o direito penal deve ser um meio para a realização dos fins 
constitucionais do e no Estado Democrático de Direito. Sendo que, nessa seara, os direitos humanos figuram como instrumentos para impor limites à violência institucional, mas não se limitam a isso.

Portanto, como já dissemos, a reformulação do sistema penal depende da participação ativa dos cidadãos, de modo a superar o paradigma punitivista em vista de outras propostas integradoras, de conciliação e reparação.

\begin{abstract}
A postura da sociedade diante da criminalidade deve ser a de tomar posição ativa na discussão do problema e das possíveis soluções, entendendo a perversidade seletiva e estigmatizante do sistema penal. A busca por uma política criminal alternativa deve ser de toda a coletividade, não podendo permanecer apenas na esfera estatal. (LOPES, 2002, p. 169)
\end{abstract}

\title{
5 CONSIDERAÇÕES FINAIS
}

Os direitos humanos são a base da cidadania e conformam os princípios do Estado Democrático de Direito, de acordo com a Constituição de 1988. Por seu turno, a moderna noção de cidadania corresponde a complexos processos de edificação dos Estados-nação, seus limites e possibilidades no que tange à consolidação de direitos civis, políticos, sociais e econômicos.

No contexto brasileiro, entendemos que a cidadania é uma construção coletiva a partir de lutas de sujeitos e grupos sociais em busca de reconhecimento e direitos (CATTONI DE OLIVEIRA, 2012). Todavia, temos visto a violação sistemática de direitos humanos e cidadãos no Brasil desde o nascer da República, de modo que precisamos problematizar os pressupostos da cidadania moderna, assim como compreender seus limites e possibilidades na periferia do capitalismo.

Logo, este artigo propôs analisar as prisões e sucessivas violações de direitos humanos do ex-catador Rafael Braga, para, a partir de então, evidenciar as estruturas que produzem no Brasil milhares de histórias semelhantes à sua. A produção de subcidadãos na periferia do capitalismo compõe a lógica do modo de produção capitalista que diante de suas necessidades de autovalorização instrumentaliza e exclui indivíduos e grupos sociais inteiros.

A cidadania moderna é insuficiente e problemática quando aplicada em sociedades plurais e diametralmente distintas da europeia, de onde advém tal modelo. No Brasil e na América Latina, o esgotamento da cultura liberal-burguesa culminou em crise do sujeito, da sociedade e das instituições políticas, de tal forma que vivemos hoje intensas crises de legitimidade que, por sua vez, abrem espaço para a profusão de teorias críticas-emancipatórias preocupadas em compreender a ideologia legitimadora do atual modelo societário, assim como propor alternativas autóctones. 
Sobretudo, essa crise evidencia-se no modelo normativo de controle social, visto que a estrutura do direito positivado não consegue atender às demandas sociais em países periféricos, nos quais as necessidades de reprodução do capital reificam os sujeitos tornandoos figuras descartáveis.

Nesse cenário a crise do capitalismo deságua em crise social, crise de legitimidade e discrepância social de vários níveis. E a história de Rafael Braga reflete um processo histórico de violação de direitos e "ausência" de direitos, mas também de lutas sociais e de classes por condições material e simbolicamente dignas.

\section{REFERÊNCIAS BIBLIOGRÁFICAS}

ALVES, Cíntia. O primeiro e único condenado das manifestações de junho de 2013. GNN/Ponte Jornalismo, 28 de agosto de 2015. Disponível em: https://jornalggn.com.br/noticia/oprimeiro-e-unico-condenado-das$\underline{\text { manifestacoes-de-junho-de-2013 }}$ Acesso: 13 ago. 2020.

Augusto, Acácio. Política e Polícia: cuidados, controles e penalizações de jovens. Rio de Janeiro: Lamparina Editora, 2013.

BRASIL. Conselho Nacional de Justiça. Perfil Sociodemográfico dos magistrados brasileiros, 2018. Disponível em: https://www.migalhas.com.br/arquivos/202 0/7/E101A56C85154D_perfildemografico. pdf Acesso: 14 ago. 2020.

BRASIL. Constituição (1988). Constituição da República Federativa do Brasil. Brasília, DF: Senado Federal: Centro Gráfico, 1988.

BRASIL. Departamento Penitenciário Nacional. Levantamento Nacional de Informações Penitenciárias. Período de julho a dezembro de 2019. Disponível em:

https://app.powerbi.com/view?r=eyJrIjoiM mU4ODAwNTAtY2IyMS00OWJiLWE3Z
TgtZGNjY2ZhNTYzZDliliwidCI6ImViM DkwNDIwLTQ0NGMtNDNmNy05MWY yLTRiOGRhNmJmZThlMSJ9 Acesso 13 ago. 2020.

BRITO, Felipe; OLIVEIRA, Pedro Rocha de. (org.). Até o último homem: visões cariocas da administração armada da vida social. São Paulo: Boitempo, 2013.

CARVAlHO, José Murilo de. Cidadania no Brasil: o longo caminho. $3^{\mathrm{a}}$ ed. Rio de Janeiro: Civilização Brasileira, 2002.

CARVALHO, Salo. Antimanual de criminologia. $5^{\text {a }}$ ed. São Paulo: Saraiva, 2013.

CATTONI DE OLIVEIRA, Marcelo Andrade. Teoria da Constituição. Belo Horizonte: Initia Via, 2012.

CRENSHAW, Kimberlé. Documento para o encontro de especialistas em aspectos da discriminação racial relativos ao gênero. Estudos Feministas, ano $10,1^{\circ}$ semestre 2002 , pp. 171-188.

CRUZ, Maria Teresa. "Rafael é a regra, não exceção", diz autor de livro sobre ex-catador. Ponte Jornalismo, $21 \mathrm{de}$ setembro de 2018. Disponível em: https://ponte.org/livro-seletividade-do- 
sistema-penal-analisa-a-condenacao-derafael-braga/ Acesso: 13 ago. 2020.

DAMATTA, Roberto. O que faz o Brasil, Brasil? Rio de Janeiro: Rocco, 1989.

FORNASIER, Mateus de Oliveira; TONDO, Ana Lara. A cidadania na América Latina e a Filosofia da Libertação: observações sobre $\mathrm{o}$ pensamento de Enrique Dussel. Revista Direitos Sociais e Políticas Públicas (UNIFAFIBE), vol. 5, n. 1, 2017, pp. 391420.

FOUCAULT, Michel. Vigiar e Punir: história da violência nas prisões. $40^{\mathrm{a}} \mathrm{ed}$. Petrópolis, RJ: Vozes, 2012.

FRASER, N. Redistribuição, Reconhecimento e Participação: por uma concepção integrada da justiça. In: SARMENTO; IKAWA; PIOVESAN (coord.). Igualdade, Diferença e Direitos Humanos. Rio de Janeiro: Editora Lumes Juris, 2008, pp. 167-189.

G1. Único condenado após atos de 2013 no Rio vai para prisão domiciliar. $G 1,01$ de dezembro de 2015. Disponível em: http://g1.globo.com/rio-dejaneiro/noticia/2015/12/unicomanifestante-condenado-no-rio-vaiparaprisao-domiciliar.html Acesso: 13 ago. 2020.

GOVERNO DO BRASIL. Dados sobre a população carcerária do Brasil são atualizados. 17 de fevereiro de 2020. Disponível em: https://www.gov.br/ptbr/noticias/justica-eseguranca/2020/02/dados-sobrepopulacao-carceraria-do-brasil-saoatualizados Acesso: 16 ago. 2020.

HUNT, Lyn. A invenção dos Direitos Humanos. São Paulo: Companhia das Letras, 2009.
JUSTIFICANDO. Leia a íntegra do Habeas Corpus de Rafael Braga que será julgado no TJ-RJ. Justificando, 31 de julho 2017. Disponível em: http://justificando.cartacapital.com.br/2017 /07/31/leia-integra-do-habeas-corpus-derafael-braga-que-sera-julgado-no-tj-rj/25 Acesso: 13 ago. 2020.

KADANUS, Kelli. População carcerária triplica em 20 anos; só $11 \%$ são presos por crimes contra a pessoa. Gazeta do Povo, 14 de fevereiro de 2020. Disponível em:

https://www.gazetadopovo.com.br/republic a/populacao-carceraria-triplica-brasil2019/ Acesso 13 ago. 2020.

KERGOAT, Danièle. Dinâmica e consubstancialidade das relações sociais. Novos Estudos 86, mar. 2010, pp. 93-103.

LAVALLE, Adrián Gurza. Cidadania, igualdade e diferença. Lua Nova, São Paulo, n 59, 2003, pp. 75-94.

LOPES, Luciano Santos. A criminologia crítica: uma tentativa de intervenção (re)legitimadora no sistema penal. De Jure, Belo Horizonte, v. 05, pp. 145-176, 2002. Disponível em: https://aplicacao.mpmg.mp.br/xmlui/bitstre am/handle/123456789/332/criminologia\% 20critica_Lopes.pdf?sequence $=1$ Acesso: 13 ago. 2020.

MBEMBE, Achille. Necropolítica. Revista do PPGAV/EBA/UFJR, Rio de Janeiro, n. 31, dez. 2016, pp. 123-151.

NOVAIS, Maysa C. dos Reis. Do chão da fábrica à fábrica carcerária. Revista de Criminologias e Políticas Criminais, Curitiba, v. 2, n. 2, Jul./Dez. 2016, pp. 117130.

OLIVEIRA, Henrique. Rafael Braga com tuberculose: a contradição da lei antidrogas que zela pela saúde pública. Carta Capital, 5 de setembro de 2017. 
Disponível

em: http://www.justificando.com/2017/09/05/ra fael-braga-com-tuberculose-contradicaoda-lei-antidrogas-que-zela-pela-saudepublica/ Acesso: 13 ago. 2020.

REDE BRASIL ATUAL. STJ autoriza prisão domiciliar para Rafael Braga. Rede Brasil Atual, 13 de setembro 2017. Disponível em: http://www.redebrasilatual.com.br/cidadani a/2017/09/stj-autoriza-prisao-domiciliarpara-rafael-braga Acesso: 13 ago. 2020.

ROUVENAT, Fernanda. Rafael Braga é absolvido do crime de associação ao tráfico de drogas. G1, 23 de novembro de 2018. Disponível em: https://g1.globo.com/rj/rio-dejaneiro/noticia/2018/11/23/rafael-braga-eabsolvido-do-crime-de-associacao-aotrafico-de-drogas.ghtml Acesso: 13 ago. 2020.

RUSCHE, Georg; KIRCHHEIMER, Otto. Punição e estrutura social. Tradução de Gizlene Neder. $2^{\mathrm{a}}$ ed. Rio de Janeiro: Revan, 2004.

SANSÃO, Luíza. Rafael Braga é preso com novo flagrante forjado, diz advogado. Pote Jornalismo, 12 de janeiro de 2016. Disponível em: https://ponte.org/rafael-braga-e-preso-comflagrante-forjado-novamente/. Acesso: 13 ago. 2020.

SOUZA, Jessé. Subcidadania Brasileira: para entender o país além do jeitinho brasileiro. São Paulo: LeYa, 2018.

VIEIRA, Oscar Vilhena. A desigualdade e a subversão do Estado de Direito. Revista Eletrônica SUR - Revista Internacional de Direitos Humanos, n. 06, ano 4, 2007, pp. 28-51.

ZAFFARONI, Eugenio Raúl; BATISTA, Nilo; ALAGIA, Alejandro; SLOKAR, Alejandro. Direito Penal Brasileiro. Teoria geral do direito penal. Rio de Janeiro: Reevan, 2003.

ZUCCO, André C.; LESCOVITZ, Guilherme; TAQUES, Lenon G. Batista. Desvendando a seletividade penal do caso Rafael Braga. Justificando, 22 de julho de 2019. Disponível em: http://www.justificando.com/2019/07/22/d esvendando-a-seletividade-penal-do-casorafael-braga/ Acesso: 13 ago. 2020.

\section{RAFAEL BRAGA'S CASE AS EVIDENCE OF SUB-CITIZENSHIP AND ITS REFLECTIONS IN THE CRIMINAL SYSTEM}

Mayara Lorena Barbosa de Almeida

How to cite this article: ALMEIDA, Mayara Lorena Barbosa de. Caso Rafael Braga como evidência da subcidadania e seus reflexos no sistema penal. Revista de Ciências do Estado. Belo Horizonte: v. 6, n. 1, 2021, e25136. ISSN: 2525-8036.

Abstract: Blatant arbitrariness and illegalities permeate the apparatus related to the Brazilian criminal system and law: militias, massacres and systematic human rights violations in prisons are recurrent and even naturalized. This work proposes to understand the system and criminal law in view of the category of sub-citizenship in the Brazilian context. Based on the case of the young Rafael Braga, who was arrested in 2013 at the June Days, we analyzed the Brazilian scenario in the light of critical theory as a method of disclosing the dominant structures and ideologies, but also as a methodology capable of showing struggles and 
emancipatory proposals. In addition, we present data that corroborate relevant social markers in the construction of crime. Our hypothesis is that Rafael Braga's case exposes the rule, and not the exception of the modern penal model that, in peripheral societies such as Brazil, shows structural inequality and the fragility of citizenship. The results point to the inadequacy of the punitive model for the effectiveness of citizenship and human rights as presuppositions of the Democratic Rule of Law. It is concluded that it is necessary to overcome the normative model of social control in order to reduce the social discrepancies that in Brazil produce sub-citizens.

Keywords: Citizenship; Penal System; Criminal Law. 